University of Warwick institutional repository: http://go.warwick.ac.uk/wrap

This paper is made available online in accordance with publisher policies. Please scroll down to view the document itself. Please refer to the repository record for this item and our policy information available from the repository home page for further information.

To see the final version of this paper please visit the publisher's website. Access to the published version may require a subscription.

Author(s): Silvia Gosiewska, Rina Soni, Guy J. Clarkson and Martin Wills

Article Title: Synthesis and use of a stable aminal derived from TsDPEN in asymmetric organocatalysis

Year of publication: 2010

Link to published article:

http://dx.doi.org/10.1016/j.tetlet.2010.06.017

Publisher statement: "NOTICE: this is the author's version of a work that was accepted for publication in Tetrahedron Letters. Changes resulting from the publishing process, such as peer review, editing, corrections, structural formatting, and other quality control mechanisms may not be reflected in this document. Changes may have been made to this work since it was submitted for publication. A definitive version was subsequently published in Tetrahedron Letters, VOL, 51,ISSUE 32, (2010) DOI:10.1016/j.tetlet.2010.06.017 


\section{Graphical Abstract}

To create your abstract, type over the instructions in the template box below.

Fonts or abstract dimensions should not be changed or altered.

Synthesis and use of a stable aminal derived
from TsDPEN in asymmetric
organocatalysis.
Silvia Gosiewska, Rina Soni, Guy J. Clarkson and Martin Wills.




\title{
Synthesis and use of a stable aminal derived from TsDPEN in asymmetric organocatalysis
}

\author{
Silvia Gosiewska, Rina Soni, Guy J. Clarkson and Martin Wills. \\ Department of Chemistry, The University of Warwick, Coventry, CV4 7AL, UK
}

\begin{abstract}
A stable aminal formed stereoselectively from $(R, R)$-N-tosyl-1,2-diphenyl-1,2-ethylenediamine (TsDPEN) is capable of asymmetric organocatalysis of Diels-Alder and $\alpha$-amination reactions of aldehydes. (C) 2011 Elsevier Science. All rights reserved
\end{abstract}

The use of enantiomerically pure amines as catalysts for organic reactions has proved to be a productive area of research. ${ }^{1-10}$ Following initial reports on the use of proline, ${ }^{2}$ several derivatives based on five-membered N-containing rings have been developed, notably pyrrolidine derivatives such as 1-4. ${ }^{3-6}$ Closely related cyclic aminals, such as $\mathbf{5 - 8}$, have also been successfully applied. ${ }^{7-10}$ Imidazolidinones $\mathbf{5}$ and $\mathbf{6}$ generate high enantioselectivity in, for example, Diels-Alder additions, $\alpha$-chlorination of ketones, Michael additions, conjugate hydride additions to enones, and aldol reactions. ${ }^{7,8}$ Aminals $\mathbf{7}$ and $\mathbf{8}$ have been employed in asymmetric $\alpha$-amination and bromination of ketones, and nucleophilic additions to enones. ${ }^{9,10}$ In this paper, we describe the synthesis of a novel class of homochiral aminal which shows activity in asymmetric organocatalytic reactions.
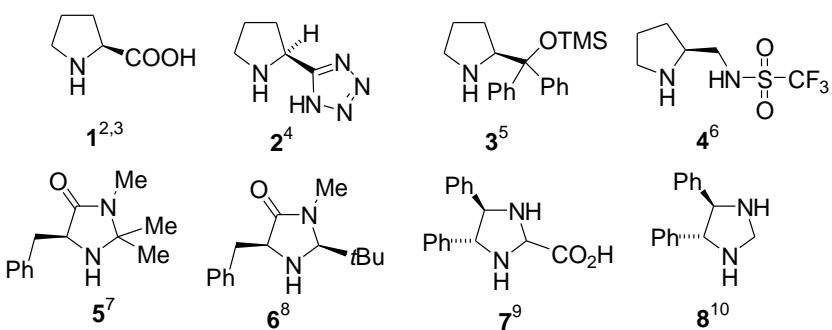

During the course of studies on the functionalisation of TsDPEN 9 via reductive alkylation, ${ }^{11}$ we found that its reaction with $\alpha$-trialkylsilyloxy-substituted aldehyde $\mathbf{1 0}$ resulted in the formation of stable aminal 11. This was not reduced in situ under conditions which we had typically used for reductive alkylation, e.g. $\mathrm{NaBH}_{3} \mathrm{CN}, \mathrm{MeOH}{ }^{11}$ Although aminal 11 could be reduced to the required product 12 (the TBDPS group was also removed in this process) using $\mathrm{LiAlH}_{4}$, it could be also readily purified by flash chromatography without hydrolysis. Significantly, 11 was formed as a single diastereoisomer in high yield upon acid-catalysed reaction of $\mathbf{9}$ with $\mathbf{1 0}$ (Scheme 1). X-ray

crystallographic analysis of a purified sample (Figure 1) revealed the relative stereochemistry illustrated, i.e. with the TBDPS group trans to the phenyl adjacent to the basic amine.

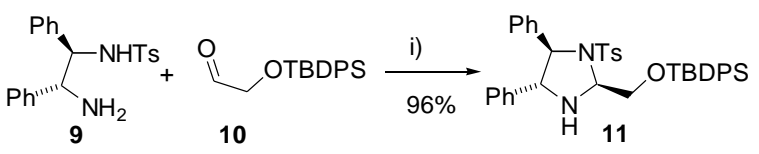

Scheme 1 Reagents and conditions. i) AcOH,reflux.

(a)

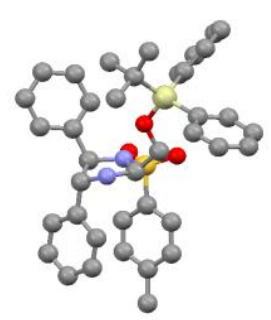

(b)

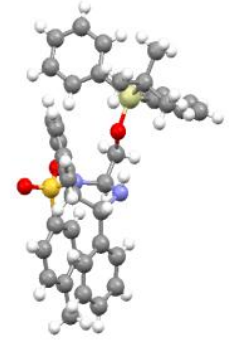

Figure $1 \mathrm{X}$-ray structure of 11. (a) $\mathrm{H}$ atoms removed for clarity, (b) with $\mathrm{H}$ atoms shown.

Given the structural similarity of $\mathbf{1 1}$ to related organocatalysts such as $\mathbf{5 - 8},{ }^{7-10}$ we chose to investigate its ability to act in this capacity. In the Diels-Alder reaction (Scheme 2, Table 1) between cyclohexadiene and acrolein, ${ }^{7 \mathrm{a}}$ using $10 \mathrm{~mol} \%$ of $\mathbf{1 1}$ as its hydrochloride salt, the predominant endo cycloaddition product was formed in up to $72 \%$ ee. Full conversion was achieved under optimised conditions (see Supporting Information for full details). The use of the salt is important; the free base gives no conversion at $5 \%$ catalyst loading, although $23 \%$ of racemic product was formed after $24 \mathrm{~h}$ using $10 \mathrm{~mol} \%$ of 11. ${ }^{7 a}$ The presence of a small amount of water in the solvent increases the rate of the reaction but does not

\footnotetext{
* Corresponding author. Tel.: +44-24-7652-3260; fax: +44-24-7652 4112; e-mail: m.wills@ warwick.ac.uk.
} 
reduce the selectivity. The product was shown to be of $S$ configuration at the atom adjacent to the aldehyde group by reduction of a sample of $72 \%$ ee to the corresponding alcohol and comparison of the sign of the optical rotation to that reported for this compound. ${ }^{12}$ This configuration would mirror that of close precedents ${ }^{7 \mathrm{a}}$ in the literature which indicate that the cycloaddition takes place through an endo transition state to the $E$ - iminium cation on the less hindered face (Figure 2).

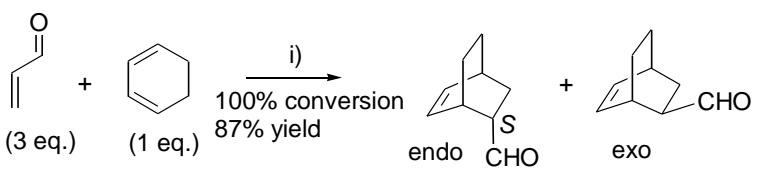

Scheme 2 Reagents and conditions. i) $10 \mathrm{~mol} \% 11 . \mathrm{HCl}, 95: 5$ $\mathrm{MeCN}: \mathrm{H}_{2} \mathrm{O}$.
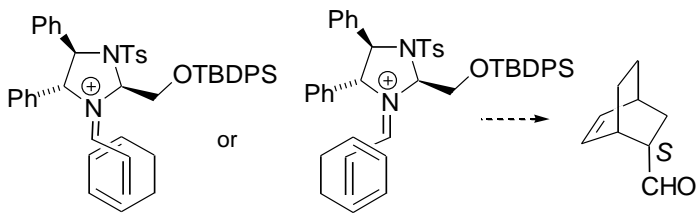

Figure 2 Control of selectivity of Diels-Alder cyclodaddition using 11. Cyclohexadiene adds to the least hindered face of each conformer of the $E$-iminium cation.

Encouraged by this result, we sought to establish whether aminal 11 remained intact under the reaction conditions, or degraded (for example by hydrolysis) to TsDPEN 9. The use of TsDPEN.HCl $(\mathbf{9} . \mathrm{HCl})$ under the same conditions gave a cycloaddition product of just $28 \%$ ee (endo:exo 10:1.5, $87 \%$ conversion in $22.5 \mathrm{~h}$ ). The reaction of $\mathbf{1 1}$ with excess acrolein gave no evidence of exchange of aldehyde with the aminal. In order to establish the importance of the silyloxy group, the analogues $\mathbf{1 3}$ and $\mathbf{1 4}$ were also prepared from TsDPEN and the corresponding aldehydes. Desilylation of $\mathbf{1 1}$ gave $\mathbf{1 5}$ in $85 \%$ yield, which was also tested.<smiles>OCCNC(c1ccccc1)[C@H](NC(=S)NC(c1ccccc1)c1ccccc1)c1ccccc1</smiles>

Benzyloxy derivative $\mathbf{1 3}$ proved to be stable and was readily purified in single diastereoisomer form (relative configuration assigned by analogy with 11). In contrast, the benzyl derivative $\mathbf{1 4}$ was prepared in low yield as a mixture of diastereomers, from which the major (relative configuration unknown) was purified by chromatography on silica gel.

The use of aminal 14 in the cycloaddition reaction (Scheme 2) gave a product with an ee similar to that obtained with 9. $\mathrm{HCl}$, and could not be recovered after the reaction, thus suggesting that it may be hydrolysed ( 9 was detected by TLC). In contrast, all of the alkoxy- and hydroxyderivatives could be reisolated from the reaction and reused. An attempt to prepare an aminal from TsDPEN and benzaldehyde did not give the required product. This difference in stability may be a result of the electronwithdrawing effect of the alkoxy group. The benzyloxy catalyst $\mathbf{1 3}$ gave a cycloaddition product of $45 \%$ ee and the hydroxy catalyst 15 , one of $44 \%$ ee, indicating that the bulkier TBDPS group is advantageous to the reaction selectivity. An attempt was made to form an aminal from trans- $N$-tosyl-1,2-cyclohexanediamine, however this failed, possibly due to a high level of strain in the bicyclic product.

Table 1. Diels-Alder reaction of acrolein and 1,3-cyclohexadiene using catalysts $\mathbf{1 1}, \mathbf{9}$ and $\mathbf{1 3 - 1 5} \cdot \mathrm{HCl}$.

\begin{tabular}{|c|c|c|c|c|c|c|c|}
\hline Entry & Catalyst & $\mathrm{mol} \%$ & Solvent & $\begin{array}{c}\mathrm{t} / \mathrm{h} \text { Conv. } \\
/ \%\end{array}$ & $\begin{array}{l}\text { Yield }^{\mathrm{b}} \\
/ \%\end{array}$ & $\begin{array}{l}\text { Endo: } \\
\text { Exo }\end{array}$ & $\begin{array}{l}\text { ee } / \%^{\mathrm{c}} \\
\text { (endo) }\end{array}$ \\
\hline 1 & 11. $\mathrm{HCl}$ & 5 & $\begin{array}{c}\mathrm{CH}_{3} \mathrm{CN} / \mathrm{H}_{2} \mathrm{O} \\
(95: 5)\end{array}$ & 83 & 38 & $12: 1$ & 67 \\
\hline 2 & $\begin{array}{c}11 \text { (free } \\
\text { base) }\end{array}$ & 5 & $\begin{array}{c}\mathrm{CH}_{3} \mathrm{CN} / \mathrm{H}_{2} \mathrm{O} \\
(95: 5)\end{array}$ & 24 & - & - & - \\
\hline 3 & 11. $\mathrm{HCl}$ & 10 & $\begin{array}{c}\mathrm{CH}_{3} \mathrm{CN} / \mathrm{H}_{2} \mathrm{O} \\
(95: 5)\end{array}$ & $24100^{d}$ & 87 & $10: 1$ & 72 \\
\hline 4 & 11. $\mathrm{HCl}$ & 15 & $\begin{array}{c}\mathrm{CH}_{3} \mathrm{CN} / \mathrm{H}_{2} \mathrm{O} \\
(95: 5)\end{array}$ & 93 & 80 & $8: 1$ & 71 \\
\hline 5 & 11. $\mathrm{HCl}$ & 5 & $\mathrm{CH}_{3} \mathrm{CN}$ (dry) & $\begin{array}{ll}180 & 83\end{array}$ & 65 & $10: 1$ & 67 \\
\hline 6 & 9. $\mathrm{HCl}$ & 10 & $\begin{array}{c}\mathrm{CH}_{3} \mathrm{CN} / \mathrm{H}_{2} \mathrm{O} \\
(95: 5)\end{array}$ & $22.5 \quad 87$ & 28 & $7: 1$ & 28 \\
\hline 7 & 13. $\mathrm{HCl}$ & 10 & $\begin{array}{c}\mathrm{CH}_{3} \mathrm{CN} / \mathrm{H}_{2} \mathrm{O} \\
(95: 5)\end{array}$ & $17100^{d}$ & 35 & $10: 1$ & 45 \\
\hline 8 & 14. $\mathrm{HCl}$ & 10 & $\begin{array}{c}\mathrm{CH}_{3} \mathrm{CN} / \mathrm{H}_{2} \mathrm{O} \\
(95: 5)\end{array}$ & $17100^{d}$ & 35 & $5: 1$ & 29 \\
\hline 9 & 15. $\mathrm{HCl}$ & 10 & $\begin{array}{c}\mathrm{CH}_{3} \mathrm{CN} / \mathrm{H}_{2} \mathrm{O} \\
(95: 5)\end{array}$ & $18.5100^{d}$ & 36 & $12: 1$ & 44 \\
\hline \multicolumn{8}{|c|}{ 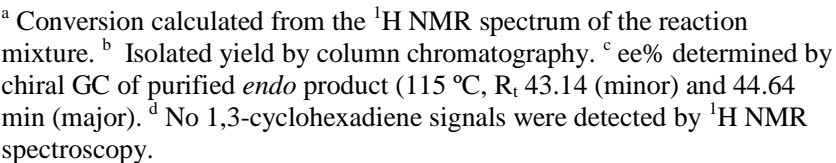 } \\
\hline
\end{tabular}

The application of aminals $\mathbf{1 1}$ and 13-15 to a series of other asymmetric organocatalytic reactions was investigated. Of these, promising results were obtained in the asymmetric addition of diethylazodicarboxylate (DEAD) (Scheme 3) $)^{3 \mathrm{a}, \mathrm{b}, 9 \mathrm{a}}$ in which addition products of up to $97.5 \%$ ee were isolated using $10 \mathrm{~mol} \%$ of $\mathbf{1 1}$. Using a relatively non-volatile aldehyde, i.e. 3-methylbutanal, in initial studies (Table 2), and $\mathbf{1 1}$ as the catalyst, the addition of a small amount of $\mathrm{AcOH}$ was found to be advantageous to the reaction rate, although the ee was not affected.

Whilst $100 \%$ conversion of DEAD (limiting reagent) to 16 was observed by NMR, this product was not isolated because it was prone to racemisation. Instead, 16 was reduced and cyclised to the configurationally stable oxazolidinone $\mathbf{1 7}$ in order to establish the ee. ${ }^{3 \mathrm{~b}}$ Since the reactions were followed by taking samples at intervals (see supporting information for graphs), the isolated yields of $\mathbf{1 6}$ and 17 were not recorded at this stage. 


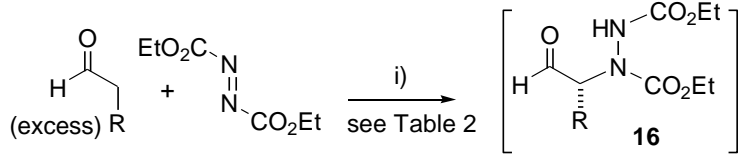

$\mathrm{R}=\mathrm{Pr}, \mathrm{Me}, \mathrm{Et}, \mathrm{CH}_{2} \mathrm{Ph} \quad 100 \%$ conversion

$\underset{\text { see Tables } 2 \text { and } 3}{\text { ii), iii) }}$

Scheme 3 Reagents and conditions. i) 2-10 mol\% 11, 9, 13-15 $\mathrm{RCO}_{2} \mathrm{H}$, neat. ii) $\mathrm{NaBH}_{4}$. iii) $\mathrm{NaOH}$.

Table 2. Reaction of DEAD with 3-methylbutanal catalysed by 11; variation of acid level, catalyst loading, and acid. ${ }^{a}$

\begin{tabular}{llllll}
\hline Entry mol\% 11 & $\begin{array}{l}\text { mol\% Acid }\left(\mathrm{CH}_{3} \mathrm{CO}_{2} \mathrm{H}\right. \\
\text { unless stated })\end{array}$ & Time $^{\mathrm{b}}$ & Temp & ee $^{\mathrm{c}}$ \\
\hline 1 & 10 & 0 & $10.0 \mathrm{~h}$ & $\mathrm{rt}$ & $96.2(R)$ \\
\hline 2 & 10 & 5 & $6.0 \mathrm{~h}$ & $\mathrm{rt}$ & $97.2(R)$ \\
\hline 3 & 10 & 10 & $4.5 \mathrm{~h}$ & $\mathrm{rt}$ & $96.6(R)$ \\
\hline 4 & 10 & 15 & $4.5 \mathrm{~h}$ & $\mathrm{rt}$ & $96.0(R)$ \\
\hline 5 & 10 & 20 & $4.5 \mathrm{~h}$ & $\mathrm{rt}$ & $95.6(R)$ \\
\hline 6 & 10 & 10 & $3.0 \mathrm{~h}$ & $40^{\circ} \mathrm{C}$ & $93.4(R)$ \\
\hline 7 & 10 & 10 & $24.0 \mathrm{~h}$ & $0-5{ }^{\circ} \mathrm{C}$ & $97.5(R)$ \\
\hline 8 & 5 & 5 & $23.5 \mathrm{~h}$ & $\mathrm{rt}$ & $96.3(R)$ \\
\hline 9 & 2 & 2 & $30.0 \mathrm{~h}$ & $\mathrm{rt}$ & $\mathrm{nd}$ \\
\hline 10 & 10 & 10 & $3.0 \mathrm{~h}$ & $\mathrm{rt}$ & $71.7(R)$ \\
\hline 11 & 10 & 10 & & & \\
\hline 12 & 10 & 10 & $6.0 \mathrm{~h}$ & $\mathrm{rt}$ & $96.2(R)$ \\
\hline $13^{\mathrm{e}}$ & 10 & 10 & & & \\
\hline $14^{\mathrm{f}}$ & 10 & 10 & $6.0 \mathrm{~h}$ & $\mathrm{rt}$ & $96.0(R)$ \\
\hline & & $4-\mathrm{NO}_{2} \mathrm{C}_{6} \mathrm{H}_{4} \mathrm{CO}_{2} \mathrm{H}$ & & & \\
\hline
\end{tabular}

${ }^{a}$ Aldehyde $=3$-methylbutanal, catalyst $(R, R)-\mathbf{1 1}, \mathrm{DEAD}$, no solvent, reactions were all followed by ${ }^{1} \mathrm{H}$-NMR (see supporting information for plots). ${ }^{b}$ time at which $100 \%$ conversion was observed by ${ }^{1} \mathrm{H}-\mathrm{NMR} .{ }^{\mathrm{c}}$ ee of cyclised product $\mathbf{1 7}$ after reduction of $16 .{ }^{\mathrm{d}}$ nd=not determined,

decomposition of DEAD was observed. ${ }^{\mathrm{e}} 3$ cycles of aldehyde and DEAD addition, without extra $\mathrm{AcOH}$. ee given for last run. ${ }^{\mathrm{f}} 3$ cycles of aldehyde, $\mathrm{DEAD}$ and $\mathrm{AcOH}$ addition, ee given for last run.

At $\mathrm{rt}\left(20-25{ }^{\circ} \mathrm{C}\right)$, using $10 \mathrm{~mol} \%$ of $\mathbf{1 1}$, the reaction was complete in $4.5 \mathrm{~h}$, whilst at slightly elevated temperature the reaction was faster but the ee was lower (entry 6). As anticipated, the reversed trend was seen at lower temperature (entry 7) which gave the highest measured ee. The level of catalyst 11 could be reduced to $5 \mathrm{~mol} \%$ without loss of enantioselectivity, however, at $2 \mathrm{~mol} \%$ the reaction was significantly slower and competing decomposition of the DEAD was observed. A number of alternative acids were investigated (entries 10-12), with the strongest acid, TFA giving the shortest reaction time, but products of lower ee were formed. Finally, the repeated addition of substrate (both with and without extra acid; entries 13 and 14) was tested and revealed that the catalyst continued to catalyse the addition in high enantioselectivity, although the reaction time increased with each addition. The lower reactivity, but retained high ee, suggest that catalyst inhibition may be taking place, rather than hydrolysis, since TsDPEN was found to give a product of much lower ee (see below). Having established satisfactory conditions, a series of catalysts were evaluated, this time with propanal as the aldehyde, both with and without added acetic acid, and with variation of the dialkyldiazodicarboxylate (Table 3).

Table 3. Comparison of catalysts with and without $\mathrm{AcOH}$; propanal addition $^{\mathrm{a}}$

\begin{tabular}{lllllll}
\hline Entry & Catalyst & Diimide & $\mathrm{AcOH} / \%$ & Time $^{\mathrm{b}}$ & Yield $^{\mathrm{c}}$ & ee (17) \\
\hline 1 & $R R \mathbf{1 1}$ & DEAD & 0 & $2 \mathrm{~h}$ & $47 \%$ & $97 \%(R)$ \\
\hline $3^{\mathrm{e}}$ & $R R \mathbf{9}$ & DEAD & 0 & $47 \mathrm{~h}$ & $42 \%$ & $32 \%(R)$ \\
\hline 4 & $R R \mathbf{9}$ & DEAD & 10 & $45 \mathrm{~min}$ & $66 \%$ & $49 \%(R)$ \\
\hline 5 & $R R \mathbf{1 3}$ & DEAD & 0 & $44 \mathrm{~h}$ & $46 \%$ & $62 \%(R)$ \\
\hline 6 & $R R \mathbf{1 3}$ & DEAD & 10 & $45 \mathrm{~min}$ & $66 \%$ & $90 \%(R)$ \\
\hline 7 & $R R \mathbf{1 4}$ & DEAD & 10 & $115 \mathrm{~min}$ & $\mathrm{crude}$ & $84 \%(R)$ \\
\hline 8 & $R R \mathbf{1 5}$ & DEAD & 0 & $5 \mathrm{~d}$ & $0^{\mathrm{d}}$ & $\mathrm{nd}^{\mathrm{f}}$ \\
\hline 9 & $R R \mathbf{1 5}$ & DEAD & 10 & $31 \mathrm{~h}$ & $37 \%$ & $61 \%(R)$ \\
\hline 10 & $R R \mathbf{1 1}$ & DiPrAD & 0 & $22.5 \mathrm{~h}$ & $99 \%$ & $\mathrm{nd}^{\mathrm{f}}$ \\
\hline 11 & $R R \mathbf{1 1}$ & D $t$ BuAD & 0 & $70.5 \mathrm{~h}$ & $68 \%$ & $\mathrm{nd}^{\mathrm{f}}$ \\
\hline
\end{tabular}

a Aldehyde = propanal, $10 \mathrm{~mol} \%$ catalyst, $\mathrm{rt}$ in all cases, neat unless otherwise stated. ${ }^{\mathrm{b}}$ time at which $100 \%$ conversion was observed by $1 \mathrm{H}-$ $\mathrm{NMR}^{\mathrm{c}}$ Isolated yield of cyclised product $\mathbf{1 7}$ after reduction of $\mathbf{1 6} .{ }^{\mathrm{d}}$ No reaction observed. ${ }^{\mathrm{e}}$ in $\mathrm{CH}_{2} \mathrm{Cl}_{2}$ solvent. ${ }^{\mathrm{f}} \mathrm{nd}=$ not determined.

After completion of the reaction (Scheme 3) the aldehyde was immediately reduced and cyclised to $\mathbf{1 7}$, for which isolated yields are given. In each case, the addition of $\mathrm{AcOH}$ significantly reduced the reaction time required for $100 \%$ conversion of DEAD to product. Aminal $\mathbf{1 1}$ gave the best results, and TsDPEN 9 gave the product in up to $49 \%$ ee. The use of the $i \mathrm{Pr}$ and $t \mathrm{Bu}$ versions of DEAD gave products in good yields but after much longer reaction times. Enantiomeric excesses were not determined in these cases. The reaction was extended to alternative carbonyl substrates, which gave mixed results. The addition of butanal and 3-phenylbutanal worked well, giving products in $97 \%$ and $84 \%$ ee respectively ( $R$ enantiomers) (see supporting information).

The formation of the product of $R$ configuration using catalyst 11 suggests a reaction via an E-enamine, either trans to the OTBDPS group or to the phenyl ring on the other side of the heterocyclic ring, depending upon the conformation of the intermediate enamine (Figure 3 ). This would be consistent with directing effects observed using diarylprolinol catalysts in which the substituent on the pyrrolidine ring acts as a blocking group to electrophile addition. ${ }^{13}$ The observation of the same sense of induction with catalyst $\mathbf{1 5}$ also suggests that the hydroxymethyl group 
is not directing the addition, i.e. via a hydrogen bond. Attempts to catalyse the addition of $\alpha$-branched aldehydes formylcyclohexane and 2-methylpropanal (i.e. a non asymmetric addition), and ketones (acetone and cyclohexanone), to DEAD were unsuccessful.

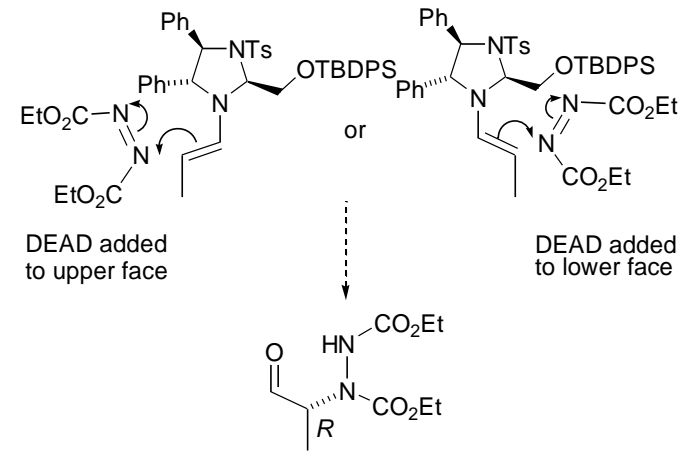

Figure 3 Addition of DEAD to E-enamine with blocking of one face by substituents on the heterocyclic ring of $\mathbf{1 1}$.

In conclusion, we have demonstrated that a stable aminal derived from TSDPEN 9 can be used as a catalyst for asymmetric $\mathrm{C}-\mathrm{C}$ and $\mathrm{C}-\mathrm{N}$ bond-forming reactions.

\section{Acknowledgements}

We thank Warwick University for financial support (Warwick Postgraduate Research Studentship to RS) and EPSRC for financial support (grant no. EP/D031168/1 to SG). Dr B. Stein and colleagues of the EPSRC National MS service (Swansea) are thanked for HRMS analyses. We acknowledge the use of the EPSRC Chemical Database Service. ${ }^{14}$ The Oxford Diffraction Gemini instrument was obtained through the Science City Project with support from the Advantage West Midlands (AWM) Advanced Materials Project and part funded by the European Regional Development Fund (ERDF).

\section{References}

1) (a) Xu, L.-W.; Lu, Y. Org. Biomol. Chem. 2008, 6, $2047-$ 2053. (b) Melchiorre, P.; Marigo, M.; Carlone, A.; Bartoli, G. Angew. Chem. Int. Ed. 2008, 47, 6138-6171. (c) Dondoni, A.; Massi, A. Angew. Chem. Int. Ed. 2008, 47, 4638-4660. (d) Connon, S. J. Chem. Commun. 2008, 2499-2410. (e) Seayad, J.; List, B. Org. Biomol. Chem. 2005, 3, 719-724. (f) Erkkilả, A.; Majander, I.; P. M. Pihko, P. M. Chem. Rev. 2008, 107, 5416-5470. (g) Mukherjee, S.; Yang, J. W.; Hoffmann, S.; B. List, B. Chem. Rev. 2007, 107, 5471-5569. (h) Lattanzi, A. Chem. Commun. 2009, 1452-1463. (i) Xu, L.-W.; Luo, J.; Y. Lu, Y. Chem. Commun. 2009, 1807-1821. (j) MacMillan, D. W. C. Nature, 2008, 455, 304-308.

2) (a) Eder, U.; Sauer, G.; Weichert, R. Angew. Chem. Int. Edn. 1971, 10, 496-497 Chemical Abstract no. 1972:59072. (b)
Hajos, Z. G.; Parrish, D. R. German Patent DE 2102623 1971, (c) Hajos, Z. G.; Parrish. D. R. J. Org. Chem. 1974, 39, 1615-1621.

3) (a) Kumaragurubaran, N.; Juhl, K.; Zhuang, W.; Bøgevig, A.; Jørgensen, K. A. J. Am. Chem. Soc. 2002, 124, 6254-6255. (b) Bøgevig, A.; Juhl, K.; Kumaragurubaran, N.; Zhuang, W.; Jørgensen, K. A. Angew. Chem. Int. Ed. 2002, 41, 1790-1793. (c) List, B.; Lerner, R. A.; Barbas III. C. F. J. Am. Chem. Soc. 2000, 122, 2395-2396.

4) (a) Cobb, A. J. A.; Shaw, D. M.; Longbottom, D. A.; Gold, J. B.; Ley, S. V. Org. Biomol.Chem. 2005, 3, 84-96. (b) Cobb, A. J. A.; Longbottom, D. A.; Shaw, D. M.; Ley, S. V. Chem. Commun. 2004, 1808-1809.

5) (a) Hayashi, Y.; Gotoh, H.; Hayashi, T.; Shoji, M. Angew. Chem. Int. Ed. 2005, 44, 4212-4215. (b) Gu, Q.; Wang, X. F.; Wang, L.; Wu, X. Y.; Zhou. Q. L. Tetrahedron: Asymmetry 2006, 17, 1537-1540.

6) (a) Wang, W.; Wang, J.; Li, H. Angew. Chem. Int. Ed. 2005, 44, 1369-1371. (b) H. Yang, H.; Carter, R. G. Org. Lett. 2008, 10, 4629-4652. (c) Mei, K.; Zhang, S.; He, S.; Li, P.; Jin, M.; Xue, F.; Luo, G.; Zhang, H.; Song, L.; Duan, W.; Wang, W. Tetrahedron Lett. 2008, 49, 2681-2684.

7) (a) Ahrendt, K. A.; Borths, C. J.; MacMillan, D. W. C. J. Am. Chem. Soc. 2000, 122, 4243-4244. (b) Kristensen, T. E.; Vestli, K.; Hansen, F. K.; Hansen, T. Eur. J. Org. Chem 2009, 30, 5185-5191. (c) Barykina, O. V.; Rossi, K. L.; Rybak, M. J.; Snider, B. B. Org. Lett. 2009, 11, 5334-5337. (d) Brochu, M. P.; Brown, S. P.; MacMillan, D. W C. J. Am. Chem. Soc. 2004, 126, 4108-4109. (e) Peelen, T. J.; Chi, Y.; Gellman, S. H. J. Am. Chem. Soc. 2005, 127, 11598-11599.

8) (a) Mangion, I. K.; Northrup, A, B.; MacMillan, D. W. C.; Angew. Chem. Int. Ed. 2004, 43, 6722-6724. (b) Contad, J. C.; Kog, J.; Laforteza, B. N.;Macmillan, D. W. C. J. Am. Chem. Soc. 2009, 131, 11640-11641. (c) Adolffsson, H. Angew. Chem. Int. Ed. 2005, 44, 3340-3342. (d) Nagib, D. A.; Scott, M. E.; Macmillan, D. W. C. J. Am. Chem. Soc. 2009, 131, 10875-10877. (e) Nicewicz, D. A.; Macmillan, D. W. C. Science 2008, 322, 77-80.

9) (a) Kotrusz, P.; Alemayehu, S.; Toma, S.; Schmalz, H.-G.; Adler, A. Eur. J. Org. Chem. 2005, 4904-4911. (b) Halland, N.; Hansen. T.; Jørgensen, K. A. Angew. Chem. Int. Ed. 2003, 42, 4955-4957.

10) Bertelsen, S.; Halland, N.; Bachmann, S.; Marigo, M.; Braunton, A.; Jørgensen, K. A. Chem. Commun. 2005, 48214823.

11) Martins, J. E. D.; Clarkson, G. J.; Wills, M. Org. Lett. 2009, 11, 847-850.

12) Cervinka, O.; Kriz, O. Collect. Czech. Chem. Commun. 1968 33, 2342-2345.

13) Franzen, J.; Marigo, M.; Fielenbch, D.; Wabnitz, T. C.; Kjaersgaard, A.; Jørgensen, K. A. J. Am. Chem. Soc. 2005, 127, 18296-18304.

14) Fletcher, D. A.; McMeeking, R. F.; Parkin,D. J. Chem. Inf. Comput. Sci. 1996, 36, 746-749.

\section{Supplementary Material}

Electronic Supplementary Information (ESI) available: experimental details, X-ray data, NMR and HPLC spectra, and graphs of experimental results. 